\title{
Flexural strength of various types of computerized machinable ceramic veneered to yttria stabilized tetragonal zirconia polycrystalline ceramic upon different hybridized techniques
}

This article was published in the following Dove Press journal:

Clinical, Cosmetic and Investigational Dentistry

Siripim Tangsatchatham '

Niwut Juntavee ${ }^{2}$

'Division of Biomaterial and Prosthodontic Research, Faculty of Dentistry, Khon Kaen University, Khon Kaen, Thailand; ${ }^{2}$ Department of Prosthodontics, Faculty of Dentistry, Khon Kaen University, Khon Kaen, Thailand
Correspondence: Niwut Juntavee Department of Prosthodontics, Faculty of Dentistry, Khon Kaen University, 123 Mitraphap Road, Khon Kaen 40002, Thailand

Tel +66897 II 2980

Email niwutpapa@hotmail.com
Objective: This study determined biaxial flexural strength (BFS) of computer-aided design/ computer-aided manufacturing (CAD/CAM) ceramic veneered yttria-stabilized tetragonal zirconia poly-crystalline (Y-TZP) related with hybridization techniques and veneering materials.

Material and methods: One hundred and twenty zirconia Y-TZP $(0.8 \mathrm{~mm}$ thick and $12 \mathrm{~mm}$ in diameter) were prepared and randomly divided into eight groups, to be conjugated with different veneering ceramics: Vitabloc (Vm), e.max-CAD (Em), Vita-Suprinity (Vs) and Celtra-Duo (Cd), using different hybridized techniques, CAD-bonded $(\mathrm{Cb})$ versus CADfused (Cf). BFS was determined using piston on three balls and analyzed for Weilbull reliability. An analysis of variance (ANOVA) and Bonferroni's multiple comparisons were determined for significant differences. Microscopic structures were examined with scanning electron microscope (SEM), along with X-ray diffraction (XRD).

Results: BFS (mean \pm sd; MPa), Weibull modulus (m), and characteristic strength $\left(\sigma_{\mathrm{o}}\right)$ of each group were $630.46 \pm 65.08,10.72$, and 659.47 for $\mathrm{VmCb}, 709.03 \pm 102.88,7.67$, and 753.03 for $\mathrm{VmCf}, 651.83 \pm 69.48,9.47$, and 685.82 for $\mathrm{EmCb}, 721.17 \pm 121.28,5.99$, and 777.04 for EmCf, $692.83 \pm 89.10,8.56$, and 731.87 for $\mathrm{VsCb}, 888.61 \pm 164.26,5.80$, and 959.08 for $\mathrm{VsCf}, 687.17 \pm 59.39,12.85$, and 713.95 for $\mathrm{CdCb}$, and $953.12 \pm 134.30,7.97$, and 1010.65 for CdCf. The BFS of ceramic veneered zirconia were significantly affected by different veneering ceramics, hybridized techniques, and their interactions $(p<0.05)$. Cd showed highest BFS, followed by Vs, Em and Vm respectively. Both $\mathrm{Cd}$ and Vs showed significant higher BFS than Em and VM $(p<0.05)$. No significant difference of BFS between $\mathrm{Cd}$ and $\mathrm{Vs}$ and between $\mathrm{Em}$ and $\mathrm{Vm}$ were indicated $(p>0.05)$. Cf technique showed significantly higher impact on BFS than $\mathrm{Cb}(p<0.05)$. Veneering zirconia with either $\mathrm{Cd}$ or Vs using Cf technique revealed significantly higher flexural strength than others combinations $(p<0.05)$.

Conclusions: Type of veneering ceramics and hybridization techniques affected BFS of ceramic veneered Y-TZP. Veneering zirconia with either Cd or Vs using Cf-process produced superior BFS.

Keywords: CAD-bonded, CAD-fused, ceramic veneered zirconia, flexural strength

\section{Introduction}

Among newly developed dental ceramics, yttria-stabilized tetragonal zirconia polycrystal (Y-TZP) is gaining popularity as an excellent surrogate to metallic material 
due to its favorable aesthetics, biological congruity, minimal bacterial plaque deposition as well as optimal fracture toughness and strength. ${ }^{1}$ Y-TZP ceramic exhibits superior mechanical properties that withstand occlusal force based on the metastatic phase transformation phenomenon that enables prevention of crack propagation. ${ }^{1}$ The strength of Y-TZP ceramic increases as the tetragonal phase $(t)$ transforms to a monoclinic phase (m) upon stress-induced metastasis; this process is described as transformation toughening prodigy. Under stressful circumstances, the t-phase transforms into the m-phase and causes a narrowing of the crack tip, which results in the prevention of further crack propagation as well as a generation of strong ceramic structure. Y-TZP ceramic offers a plethora of applications that has proved to become as diverse as frameworks for single crowns or frameworks for fixed partial denture prostheses. ${ }^{1}$ These frameworks are veneered with either feldspathic porcelain or a relatively weaker ceramic material because, from an esthetic view point, the Y-TZP ceramic possesses only basic white to ivory color, low light transmission, and relatively high refractive index, which do not permit an optimal, esthetic, and pleasing result. ${ }^{2}$ The zirconia framework is very strong with approximately 1,000 MPa for flexural strength testing; however, its weakness lies in the veneering ceramics, which have a flexural strength of approximately 100-400 MPa. Systematic reviews of veneered zirconia restorations revealed that veneering glass ceramic chipped and delaminated (15-36\%) over the course of 5 years. ${ }^{3-5}$ Meanwhile, the framework only experienced a $0-8 \%$ chip/ delamination rate. ${ }^{3-6}$ Though a unique eminent translucent yttrium-stabilized monolithic zirconia has been presented for the fabrication of entire solid restorations, it still has not achieved desirable levels of translucency. ${ }^{7}$ Thus, this condition confines its use as full, contoured restorations only in the non-visible area of the dental arch though it is still mainly used as a framework veneered with feldspar. ${ }^{8}$ Many methods attempt to mitigate the likelihood of veneered zirconia chipping, each of which has been significantly studied. Such methods include: the optimization of the firing protocol, the improvement of the framework design, the minimization of errors in the fabrication process, and the use of pressed veneer ceramics. ${ }^{9-11}$ However, the most recent approach to improving the longevity of veneered zirconia restorations has been to utilize $\mathrm{CAD} /$ CAM technology to produce both the veneer and the framework. This produced near perfect, pore-less blanks that are expected to improve the reliability of the restorations. ${ }^{12,13}$ Lithium disilicate glass-ceramic was created to have more structural integrity than feldspathic porcelains and is consequently, a suitable alternative veneering material for Y-TZP ceramic. ${ }^{13}$ Latterly, zirconium reinforcing lithium silicate (ZLS) was launched to be used with CAD/CAM. ZLS possesses the positive characteristics of both its predecessors-it is strong as well as visually pleasing. ${ }^{14,15}$ It improves both the strength and the esthetic appeal of lithium disilicate glass-ceramic. ${ }^{16}$ Since it is relatively new, its effect as a veneering material has not yet been investigated, and so, more welldesigned studies are needed to confirm such benefits. In CAD/CAM-fabricated ceramic veneering Y-TZP, both components are joined either by the fusion technique, which utilizes fusion glass ceramics (CAD-fused; Cf), or bonding technique, which uses resin adhesive (CADbonded; $\mathrm{Cb}$ ). The fusion technique has been described as providing a homogeneous, multi-layered structure, without introducing additional complications. ${ }^{10,13}$ The $\mathrm{Cb}$ technique has often been used in advanced reconstruction of implant restoration as a commonly used technique of assembling veneering ceramic to Y-TZP. As these are already established techniques, adequate literature on the multilayer structure of both the $\mathrm{Cf}$ and the $\mathrm{Cb}$ techniques with new materials is lacking. ${ }^{9,17}$

The strength and survival of a bilayer-ceramic restoration is predominantly determined by the composition and strength of substructures and veneering materials, the behavior of the interfaces, and the compatibility of veneering and substructure. ${ }^{18}$ Nevertheless, the overall strength of the bi-layered restorations is a product of multiple elements, for instance, the coefficients of linear thermal expansion (CTE) matching between each layer, ${ }^{19-24}$ residual stress, ${ }^{25,26}$ modulus of elasticity and fracture resistance of each layer, ${ }^{27,28}$ interfacial bonding strength, ${ }^{19}$ or firing numbers. ${ }^{9,25}$ As the strength of dental restorative materials is a critical foundation for acceptable restoration, a combination between the computerized machinable ceramics veneered on translucence zirconia need to be addressed. This study attempted to appraise the biaxial flexural strength of computerized machinable ceramic veneered translucence zirconia upon varying ceramic veneering materials and different hybridization techniques. The null-hypotheses proposed that the flexural strength of ceramic veneering Y-TZP, vis-a-vis the different types of ceramic veneering material and ceramic veneering techniques were not significantly affected. 


\section{Materials and methods}

The specimens fabricated according to the manufacturer's instructions in disc shape using Y-TZP material (Bruxzir, Prismatik Dentalcraft, Hannover, Germany) were used as the core material and veneered with different computerized machinable ceramics including feldspathic- (VITABLOCS; Vm, VITA-Zahnfabrik, Bad Sackingen, Germany), lithium di-silicate-based glass- (IPS e.max-CAD; Em, IvoclarVivadent, Schaan, Leichtenstein), zirconia-reinforced glass(VITA-SUPRINITY; Vs, VITA-Zahnfabrik, Bad Sackingen, Germany), and zirconia-reinforced lithium silicate(CELTRA-DUO; Cd, DENTSPLY, Hanau-Wolfgang, Germany) veneering ceramic.

\section{Preparation of computerized machinable zirconia substructure}

The pre-shade (A2) partially-sintered Y-TZP monolithic ceramic blocks were prepared in a disc shape in a diameter $(\Phi)$ of $15 \mathrm{~mm}$ and thickness of $1 \mathrm{~mm}$ using slow speed separating machine (Isomet-1000, Buehler Co., Lake Bluff, IL, USA) ( $\mathrm{n}=120)$. The surface irregularities were removed and flattened by polishing it with silicon carbide abrasive paper up to grit no. 1500 under a water coolant on the grinding machine Ecomet $^{\mathrm{TM}} 3$, Buehler, Lake Bluff, IL, USA). The pre-sintered zirconia disc then acquired full maturity for crystallization in a sintering furnace (HiTherm, Hint-ELs GmbH, Griesheim, Germany) to derive a fully sintered Y-TZP disc of $12 \mathrm{~mm} \Phi$ and $0.8 \mathrm{~mm}$ thickness, due to $20 \%$ sintering shrinkage of zirconia. The zirconia discs were aimlessly separated to 4 groups of veneering materials $(n=30)$ based on ceramic veneering materials.

\section{Preparation of computerized machinable veneering ceramic}

Each type of the pre-shade (A2) veneering ceramic blocks was sectioned in disc shape ( $n=30 /$ type) using slow speed sectioning machine and surface-polished with silicon carbide abrasive paper with grit no. 500, $800,1,200$, and 1,500 under a water coolant on the grinding machine to derive the final dimension of $12 \mathrm{~mm} \Phi$ and $0.8 \mathrm{~mm}$ thickness. Each type of veneering ceramics was unintentionally divided into 2 subgroups $(\mathrm{n}=15)$ according to hybridization techniques, viz., CAD-bonded $(\mathrm{Cb})$ and CAD-fused $(\mathrm{Cf})$, to derive the final ceramic veneered zirconia that has a thickness of $0.8 \mathrm{~mm}$ Y-TZP core material, $0.04 \mathrm{~mm}$ hybridizing agent, and $0.8 \mathrm{~mm}$ veneering ceramic, after being gauged with a digital electronic caliper (Digimatic caliper, Mitutoyo, Kawasaki, Japan).

\section{CAD-bonded hybridization technique}

For the $\mathrm{Cb}$ technique, the Y-TZP discs were sandblasted with 50 microns aluminous oxide abrasive in a sandblasting machine (Vario basic, Renfert, Hilzingen, Germany) with 2.5 bar pressure, 45 degrees directly to the disc surface and the disc surface just $10 \mathrm{~mm}$ from the blasting tip, for 15 seconds; it was then cleaned with distilled water in ultrasonic cleanser (Vitasonic-II, VITA-Zahnfabrik, Bad Sackingen, Germany) for 15 minutes, following which a metal-zirconia primer (Monobond Plus, Ivoclar Vivadent, Schaan, Leichtenstein) was applied on it. The veneering disc was acid-etched with 5\% concentrated hydrofluoric etchant (Ivoclar-Vivadent, Schaan, Leichtenstein) for 20 seconds, cleaned by spraying with distilled and air-dried, following which a metal-zirconia primer was applied onto the etched surfaces; this was followed by an application of a thin coat of resin adhesive (Variolink Esthetic, Ivoclar-Vivadent, Schaan, Leichtenstein) on the veneering ceramics surface. Following this, the veneering ceramic became one with the zirconia disc with a controlled cement film thickness of 40 micrometers $(\mu \mathrm{m})$ on a digital electronic caliper and cured with light curing unit (Mini-LED, Acteon, Norfolk, England) for 9 minutes.

\section{CAD-fused hybridization technique}

For the CAD-fused technique, the zirconia disc and the veneering ceramics disc were conjugated with a fusion glass paste (e.max CAD Crystall-connect, IvoclarVivadent, Schaan, Leichtenstein). The powder-liquid creamy mixture of the fusion glass was gently coated on the entire bonding surface of the veneering ceramics and immediately pressed manually to the zirconia disc with controlled film thickness to be exactly $40 \mu \mathrm{m}$. The excess fusion material was expelled with a micro-brush prior to firing in the porcelain-firing furnace (Programat P310, Ivoclar Vivadent, Schaan, Leichtenstein) simultaneously, using the ceramic sintering process and crystallization, according to the manufacturer's recommendation for the firing schedule.

\section{Biaxial flexural strength tests}

Strength was appraised by means of a bi-axial flexural strength testing method using piston-on-three balls technique. The supporting balls that were $3 \mathrm{~mm}$ in $\Phi$ were 

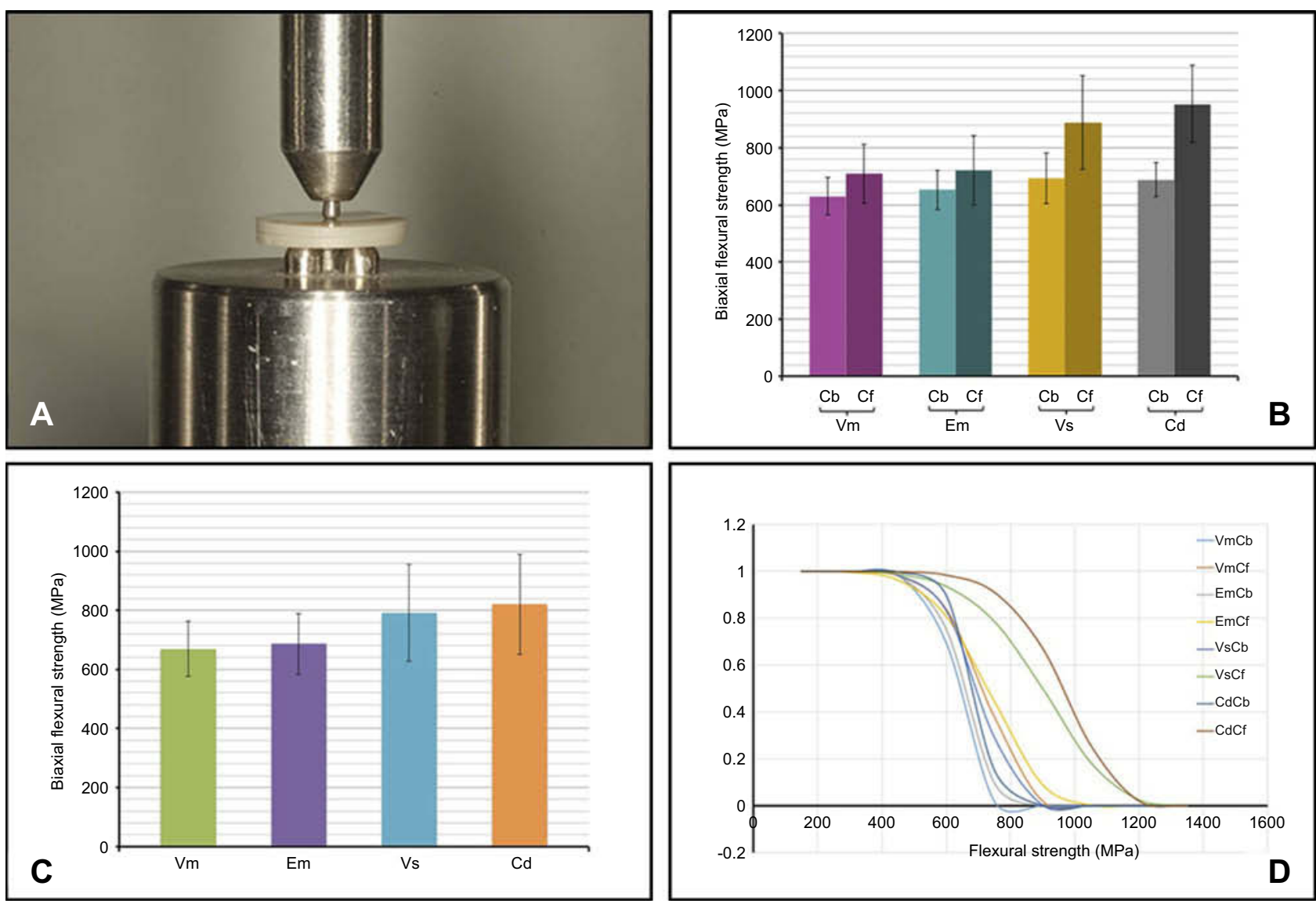

Figure I Pistol-on-three balls testing apparatus with specimen in place (A) for determination of biaxial flexural strength (BFS) for Vitabloc (Vm), e.max CAD (Em), Vita Suprinity (Vs), Celtra Duo (Cd) ceramic veneered zirconia with either CAD-bonded (Cb) or CAD-fused (Cf) technique (B), indicated effect of types veneering ceramic on fracture strength $(\mathbf{C})$, which manifested reliability of strength upon Weibull analysis curves (D).

arrayed in a circular arrangement of $5 \mathrm{~mm}$ in $\Phi, 120^{\circ}$ angle apart from each other. A plastic sheet of $0.05 \mathrm{~mm}$ thick was placed on the veneered surface in the midst of the ceramic veneered zirconia disc and the piston so as to expedite a uniform force distribution and minimize the stress concentration effect. A compressive load was applied on the veneering surface with a universal test machine (LR-30k, Lloyd Co., Leicester, England) through piston (1.4 $\mathrm{mm}$ in $\Phi)$ directly at a center of specimen, as shown in Figure 1A. The compressive load was induced at $0.5 \mathrm{~mm} /$ minute of crosshead speed until ceramic bilayer fracture. The failure load was determined and calculated as the biaxial flexural strength (BFS) by Roark's formulas ${ }^{29}$ derived from the Equations 1-5.

$$
\begin{gathered}
\sigma=\frac{6 M}{t_{2}^{2} K_{p}}\left[\frac{E_{1} t_{1}\left(1-v_{2}^{2}\right)}{E_{2} t_{2}\left(1-v_{1}^{2}\right)}+\frac{t_{2}}{t_{1}} \frac{\left(1-v_{2}^{2}\right)\left(1+t_{1} / t_{2}\right)\left(1+E_{2} t_{2} / E_{1} t_{1}\right)}{\left(1+E_{1} t_{1}\right)^{2}-\left(v_{2}+\left(v_{1} E_{2} t_{2} / E_{1} t_{1}\right)^{2}\right.}\right] \\
K_{p}=1+\frac{E_{1} t_{1}^{3}\left(1-v_{2}^{2}\right)}{E_{2} t_{2}^{3}\left(1-v_{1}^{2}\right)}+\frac{3\left(1-v_{2}^{2}\right)\left(1+t_{1} / t_{2}\right)^{2}\left(1+\left(E_{2} t_{2}\right) /\left(E_{1} t_{1}\right)\right.}{\left(1+\left(E_{2} t_{2}\right) /\left(E_{1} t_{1}\right)\right)^{2}-\left(v_{2}+\left(v_{1} E_{2} t_{2} / E_{1} t_{1}\right)^{2}\right.}
\end{gathered}
$$




$$
M=\frac{P}{8 \pi}\left\{\left(1+v_{e}\right)\left[1+2 \ln \left(\frac{a}{c}\right)\right]+\left(1-v_{e}\right)\left[1-\frac{c^{2}}{2 a^{2}}\right] \frac{a^{2}}{R^{2}}\right\}
$$

$$
\begin{gathered}
v_{e}=v_{2} \frac{K_{q}}{K_{p}} \\
K_{q}=1+\frac{E_{1} v_{1} t_{1}^{3}\left(1-v_{2}^{2}\right)}{\left.E_{2} v_{2} t_{2}^{3}\left(1-v_{1}^{2}\right)\right)} \\
+\frac{3\left(1-v_{2}^{2}\right)\left(1+t_{1} / t_{2}\right)^{2}\left(1+\left(v_{1} E_{2} t_{2} / v_{2} E_{1} t_{1}\right)\right.}{\left(1+E_{2} t_{2} / E_{1} t_{1}\right)^{2}-\left(v_{2}+\left(v_{1} E_{2} t_{2} / E_{1} t_{1}\right)^{2}\right.}
\end{gathered}
$$

In which: $\sigma=$ biaxial flexural strength; $M=$ bending moment per unit length; $P=$ load (newton); $E_{I}=$ elastic modulus of zirconia $=210 \mathrm{GPa} ; E_{2}=$ elastic modulus of veneering ceramic $(\mathrm{Vm}=65 \mathrm{GPa}, \quad E m=95 \mathrm{GPa}, \quad \mathrm{Vs}$ and $\mathrm{Cd}=70 \mathrm{GPa})$; $t_{1}=$ thickness of zirconia $(0.8 \mathrm{~mm}) ; t_{2}=$ the thickness of veneering ceramic $(0.8 \mathrm{~mm}) ; v_{1}$ and $v_{2}=$ Poisson's ratio of zirconia (0.3) and veneering ceramic (0.25); $v_{e}=$ equivalent Poisson's ratio of the bilayer; a=radius of the supporting ring $(2.5 \mathrm{~mm}) ; c=$ radius of piston ball $(0.7 \mathrm{~mm}) ; R=$ radius of specimen $(0.6 \mathrm{~mm})$.

\section{Microscopic examination}

The fractured surface, the cross sectional surface of ceramic veneered zirconia interface, and the zirconia surface specimens in each group were cleaned with ultrasonic vibrator in distilled water, dried in the desiccator (Nokko, NikkoMaterials Co, Tokyo, Japan), and surface-coated with palladium-gold in the sputtering machine (K-500X, Emitech, Asford, England) using $10 \mathrm{~mA}$ current in 130 Torr of vacuum for 3 minutes, prior to evaluation for microscopic fractured phenomenon, quality of hybridization between zirconia substructures and veneering layers, and zirconia crystal size using scanning electron microscopy (SEM; S-3000N, Hitachi Co., Osaka, Japan). The crystal structures of zirconia were determined for the comparative quantity of $\mathrm{t}$ - and $\mathrm{m}$-phase of Y-TZP by mean of X-ray diffractometry (XRD). The specimens were copper k-alpha $(\mathrm{Cu} \mathrm{K} \alpha)$ radiant-scanned from $20-40^{\circ}$ of Bragg angle (2 $\theta$ ) using $0.02^{\circ}$ step-size every 2 seconds. The crystalline phases were comparatively determined in consideration with a standard database of diffraction standards X-Ray diffractometry, computed for corresponding $d$-values using Bragg formula, as given in Equation 6.

$$
\lambda=d 2 \sin \theta
$$

Where: $\lambda$ is CuKa wavelength $(0.15418 \mathrm{~nm}), d$ is distance of planes in hkl-Miller indices

The crystalline amount of zirconia was calculated for the proportion of $\mathrm{t}$ - to $\mathrm{m}$ - phase from the intensities of peaks using software (X'Pert-Plus, Phillips, Almelo, Netherlands). The quantitative portion of the $\mathrm{m}$ - phase in relation to total crystalline phases was computed with Garvie-Nicholson and Toraya formula as given in Equations 7-9.

$$
\begin{gathered}
x_{m}=\frac{I_{m}(111)+I_{m}(\overline{\mathrm{I}} 11)}{I_{m}(111)+I_{m}(\overline{\mathrm{I}} 11)+I_{t}(101)} \\
x_{m}=\frac{C x_{m}}{1+(C-1) x_{m}} \\
x_{t}=1-x_{m}
\end{gathered}
$$

Where: $I_{m} \& I_{t}$ are intensities of $m$ - \& $t$ - phase, $C$ is correction factor (1.32), $X_{m} \& X_{t}$ are fractions of $m-\&$ t-phase

\section{Statistical analysis}

The data was statistically analyzed using IBM SPSS statistics 19.0 for Windows (SPSS version 19, SPSS, Inc., Chicago, IL). An analysis of variance (ANOVA) was performed for determination of significant differences of biaxial flexure strength related to the different veneering ceramics and hybridizing techniques. The Bonferroni's post-hoc multiple comparisons were analyzed to conclude for significant difference among each variable at $\alpha=0.05$. The appraisement for reliability of the fracture resistance was estimated from the Weibull statistical analysis (Weibull $++\circledR$, ReliaSoft, Tucson, AZ, USA) and computed for Weibull modulus $(\mathrm{m})$ and $\sigma_{o}$ : Weibull characteristic strength as given in Equation 10 along with the slope of the line plotted between $\ln \left\{\ln \left(1 / P_{\mathrm{s}}\left(V_{\mathrm{o}}\right)\right\}\right.$ against $m \ln \left(\sigma / \sigma_{\mathrm{o}}\right)$.

$$
P_{s}\left(V_{\mathrm{O}}\right)=\exp \left\{-\left(\sigma / \sigma_{\mathrm{O}}\right)^{m}\right\}
$$

Where: $P_{s}\left(V_{o}\right)$ is the probability of survival; $V_{o}$ is the volume of sample; $\sigma$ is flexural strength

\section{Results}

The mean \pm standard deviation (SD; MPa) and 95\% confidence level of BFS, $\mathrm{m}, \sigma o$, grain size distribution, relative phase concentration, and percent phase change compared to zirconia for each group were presented in Table 1 and Figure 1B and C. An ANOVA indicated a statistically significant difference in BFS as a result of 
Table I Mean, standard deviation (SD), 95\% confidential interval $(\mathrm{Cl})$, Weibull modulus $(\mathrm{m})$, characteristic strength $\left(\boldsymbol{\sigma}_{\circ}\right)$ of biaxial flexural strength $(\mathrm{MPa})$, grain size distribution (\%), relative phase content (wt.\%), and percentage of tetragonal (t-) change to monoclinic (m-) phase of Vitabloc $(\mathrm{Vm})$, e.max CAD (Em), Vita Suprinity (Vs), Celtra Duo (Cd) computerized machinable ceramic veneered zirconia with either CAD-bonded $(\mathrm{Cb})$ or $C A D$-fused $(\mathrm{Cf})$ technique

\begin{tabular}{|c|c|c|c|c|c|c|c|c|c|c|}
\hline \multirow[t]{2}{*}{ Group } & \multirow[t]{2}{*}{$\mathbf{n}$} & \multirow{2}{*}{$\begin{array}{l}\text { Flexural strength } \\
\text { Mean } \pm \text { SD } \\
(\text { LL-UL of } 95 \% \mathrm{Cl})\end{array}$} & \multirow[t]{2}{*}{$\mathbf{m}$} & \multirow[t]{2}{*}{$\sigma_{o}$} & \multicolumn{3}{|c|}{ Grain size distribution (\%) } & \multicolumn{2}{|c|}{ Relative phase } & \multirow{2}{*}{$\begin{array}{l}\mathbf{t} \rightarrow \mathbf{m} \\
(\%)\end{array}$} \\
\hline & & & & & Fine & Medium & Large & m-phase & t-phase & \\
\hline $\mathrm{VmCb}$ & 15 & $\begin{array}{l}630.46 \pm 65.08 \\
(594.4 I-666.50)\end{array}$ & 10.72 & 659.47 & 40.98 & 57.38 & 1.64 & 0.13 & 0.87 & 8.78 \\
\hline $\mathrm{VmCf}$ & 15 & $\begin{array}{l}709.03 \pm 102.88 \\
(652.06-766.00)\end{array}$ & 7.67 & 753.03 & 33.33 & 64.81 & 1.85 & 0.20 & 0.80 & 15.75 \\
\hline $\mathrm{EmCb}$ & 15 & $\begin{array}{l}651.83 \pm 69.48 \\
(613.35-690.30)\end{array}$ & 9.47 & 685.82 & 27.78 & 68.52 & 3.70 & 0.09 & 0.91 & 5.09 \\
\hline $\mathrm{EmCf}$ & 15 & $\begin{array}{l}721.17 \pm|2| .28 \\
(654.00-788.33)\end{array}$ & 5.99 & 777.04 & 30.51 & 64.41 & 5.08 & 0.15 & 0.85 & 11.07 \\
\hline $\mathrm{VsCb}$ & 15 & $\begin{array}{l}692.83 \pm 89.10 \\
(643.48-742.17)\end{array}$ & 8.56 & 731.87 & 24.53 & 71.70 & 3.77 & 0.11 & 0.89 & 6.49 \\
\hline $\mathrm{VsCf}$ & 15 & $\begin{array}{l}888.61 \pm 164.26 \\
(797.64-979.58)\end{array}$ & 5.80 & 959.08 & 35.48 & 62.90 & 1.61 & 0.19 & 0.81 & 15.54 \\
\hline $\mathrm{CdCb}$ & 15 & $\begin{array}{l}687.17 \pm 59.39 \\
(654.28-720.06)\end{array}$ & 12.85 & 713.95 & 37.50 & 56.25 & 8.33 & 0.09 & 0.91 & 4.70 \\
\hline $\mathrm{CdCf}$ & 15 & $\begin{array}{l}953.12 \pm 134.30 \\
(878.75-1027.49)\end{array}$ & 7.97 & 1010.65 & 30.77 & 65.38 & 3.85 & 0.18 & 0.82 & 14.15 \\
\hline
\end{tabular}

Abbreviations: LL, lower limit; UL, upper limit; $\mathrm{Cl}$, confidential interval; SD, standard deviation; $\mathrm{n}$, sample size; $\mathrm{m}$, Weibull modulus; $\sigma_{\circ}$, characteristic strength; $\mathrm{m}$-, monoclinic-; t-, tetragonal-; Vm, Vitabloc; Em, e.max CAD; Vs, Vita Suprinity; Cd, Celtra Duo, Cb, CAD-bond; Cf, CAD-fuse.

varied veneering ceramics, hybridized techniques, and their interaction $(p<0.05)$, as presented in Table 2 . Bonferroni's post-hoc multiple comparisons revealed that different veneering materials had a significant impact on BFS $(p<0.05)$, except for no difference between Vm versus Em and Vs versus $\mathrm{Cd}(p>0.05)$, as presented in Table 3. The assessment of reliability for fracture resistance indicated that the modulus of Weibull was comparatively ranked from highest to lowest just as $\mathrm{CdCb}>\mathrm{VmCb}>\mathrm{EmCb}>\mathrm{VsCb}>\mathrm{CdCf}>\mathrm{VmCf}>\mathrm{EmCf}>\mathrm{VsCf}$, which indicated the order of authenticity fracture resistance for computerized machinable ceramic veneered translucence zirconia as shown in Figure 1D and Table 1.

The SEM photomicrographs exhibited distinction in the size of crystal particle upon the variation in hybridization technique, as presented in Table 2 and Figure 2A and B. Microstructures at the core-veneer interface of both intact and fractured specimens of tested groups were observed. The SEM of the intact specimens of tested group was shown in Figure 2C and D. From the

Table 2 An analysis of variance (ANOVA) of biaxial flexural strength of computerizes machinable ceramic veneered yttria-stabilized tetragonal zirconia related with different hybridization techniques and veneering materials

\begin{tabular}{|l|l|l|l|l|l|}
\hline Source & SS & df & MS & F \\
\hline Corrected Model & $1403746.96 \mathrm{a}$ & 7 & 200535.280 & 17.660 & P \\
Intercept & 66027939.89 & 1 & 66027939.89 & 5814.838 & 0.000 \\
Veneering material & 503431.983 & 3 & 167810.661 & 14.778 & 0.000 \\
Hybridization technique & 696877.647 & 1 & 696877.647 & 61.371 & 0.000 \\
Veneer material * Hybridization & 203437.331 & 3 & 67812.444 & & 5.972 \\
Error & 1271768.795 & 112 & 11355.079 & & \\
Total & 68703455.64 & 120 & & & \\
Corrected Total & 2675515.756 & 119 & & & \\
\hline
\end{tabular}

Abbreviations: SS, sum of squares; MS, mean square; df, degree of freedom; F, F-ratio. 
Table 3 Post hoc Bonferroni's multiple comparisons of biaxial flexural strength (BFS) of of Vitabloc (Vm), e.max CAD (Em), Vita Suprinity (Vs), Celtra Duo (Cd) computerized machinable ceramic veneered zirconia with either CAD-bonded (Cb) or CAD-fused (Cf) technique

A. Post hoc Bonferroni's multiple comparison of BFS as a function of sintering temperature

\begin{tabular}{l|l|l|l|l}
\hline Veneer ceramic & Vitabloc & e.max CAD & Vita Suprinity & Celtra Duo \\
\hline Vitabloc & 1.000 & 1.000 & 0.000 & 0.000 \\
e.max CAD & & 1.000 & 0.001 & 0.000 \\
Vita Suprinity & & 1.000 & 1.000 \\
Celtra Duo & & & & 1.000 \\
\hline
\end{tabular}

B. Post hoc Bonferroni's multiple comparison of BFS as combinative factors among groups

\begin{tabular}{|c|c|c|c|c|c|c|c|c|}
\hline Group & $\mathrm{VmCb}$ & VmCf & $\mathrm{EmCb}$ & EmCf & $\mathrm{VsCb}$ & VsCf & $\mathrm{CdCb}$ & $\mathrm{CdCf}$ \\
\hline $\mathrm{VmCb}$ & 1.000 & 1.000 & 1.000 & 0.603 & 1.000 & 0.000 & 1.000 & 0.000 \\
\hline VmCf & & 1.000 & 1.000 & 1.000 & 1.000 & 0.000 & 1.000 & 0.000 \\
\hline $\mathrm{EmCb}$ & & & 1.000 & 1.000 & 1.000 & 0.000 & 1.000 & 0.000 \\
\hline EmCf & & & & 1.000 & 1.000 & 0.001 & 1.000 & 0.000 \\
\hline $\mathrm{VsCb}$ & & & & & 1.000 & 0.000 & 1.000 & 0.000 \\
\hline VsCf & & & & & & 1.000 & 0.000 & 1.000 \\
\hline $\mathrm{CdCb}$ & & & & & & & 1.000 & 0.000 \\
\hline $\mathrm{CdCf}$ & & & & & & & & 1.000 \\
\hline
\end{tabular}

Abbreviations: BFS, biaxial flexural strength; Vm, Vitabloc; Em, e.max CAD; Vs, Vita Suprinity; Cd, Celtra Duo, Cb, CAD-bond; Cf, CAD-fuse.

cross sectional core-veneer ceramics, the interface between the veneer versus resin cement and that between the resin cement and zirconia substructure were welldifferentiated as shown in Figure $2 \mathrm{C}$ while the interface between the veneer versus glass fusing ceramic and that between the glass fusing ceramic and zirconia substructure were well integrated. These homogeneous bonds were clearly visible on both material interfaces in Figure 2D. The SEM of the fracture specimens of tested groups indicated that hackles and lines were perpendicular to the crack origin in $\mathrm{Cb}$ groups as shown in Figure 2E whereas most of the fracture patterns in Cf groups were oblique, as manifested in Figure 2F. The XRD-microscopy indicated that the spectral positions of crystal phase harmonized with the correlating $\mathrm{t}$ - and $\mathrm{m}$-forms for $\mathrm{ZrO} 2$ within the resolution of the data. The amount $\mathrm{t} \rightarrow \mathrm{m}$ phase conversion was higher for CAD-fused- than CAD-bonded technique as shown in Figure $3 \mathrm{~A}$ and $\mathrm{B}$ and Table 1.

\section{Discussion}

The present study indicated that the flexural strength of the $\mathrm{CAD} / \mathrm{CAM}$ fabricated ceramic veneered zirconia was affected by veneering ceramics, hybridized techniques, and their interaction. Thus, the null hypothesis was rejected. The study revealed that $\mathrm{Cd}$ had significantly higher influence on the flexural strength than Vs, Em, and $\mathrm{Vm}$, respectively. The reasons might be the differences in the characteristics of strength among veneering ceramics, in which the ZLS, including Vs and $\mathrm{Cd}$, had a flexural strength of approximately $420 \mathrm{MPa}$, while the lithium di-silicate glass ceramic as Em had a flexure strength of 360-400 MPa and feldspathic ceramic as Vm exhibited a flexural strength of about $154 \mathrm{MPa}$, thus having a relatively different influence on veneering zirconia. The Cf technique showed higher characteristic strength when compared to the $\mathrm{Cb}$ technique. This is probably because of the strength of the hybridization technique as the flexural strength of fusion glass $(160 \mathrm{MPa})$ is higher than that of resin adhesive (100 MPa). The capability of the $\mathrm{Cf}$ in resistance to fracture was more than $\mathrm{Cb}$ possibly correlated with the $\mathrm{t}-\rightarrow \mathrm{m}$ - phase conversion that is capable of enduring ceramic veneered zirconia through the conversion strengthening prosperity of zirconia. ${ }^{1}$ However, the $\mathrm{m}$ for $\mathrm{Cf}$ - is lower than $\mathrm{Cb}$-technique, which indicated that the $\mathrm{Cf}$ had a higher sensitivity to fracture than $\mathrm{Cb}$. The results were in agreement with a study about the impact of the veneering method on the resistance to the fracture of molar crowns when comparing the ceramic bonded- (using Multilink Implant; Ivoclar Vivadent as a resin cement) and ceramic fused zirconia techniques, which indicated that the CAD-bonded technique tend to generate lower resistance to fracture than the 

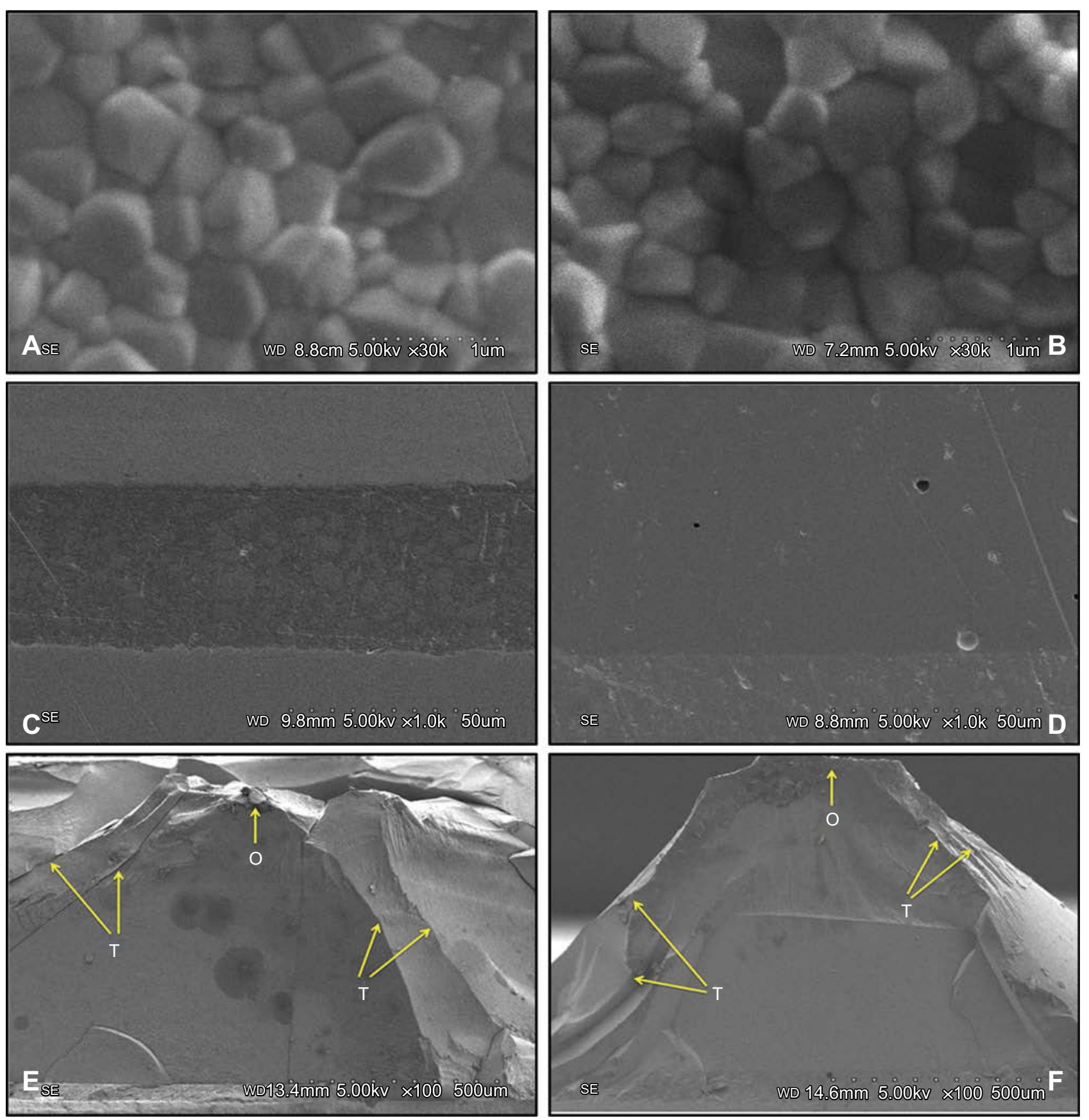

Figure 2 SEM photomicrographs display zirconia grains for CAD-bonded- (A) and CAD-fused group (B), ceramic veneered zirconia interface for CAD-bonded- (C) and CAD-fused group (D), and fracture surfaces for CAD-bonded- $(E)$ and CAD-fused group (F) indicated origin of fracture $(O)$ and twist hackle $(T)$.

CAD-fused technique. However, the difference was not statistically significant in the non-artificial aging group. ${ }^{28}$ Nevertheless, upon employing the artificial aging procedure with the simulation process of chewing, none of the specimens in either CAD-bonded- or CAD-fused groups failed; this showed that both hybridization techniques were capable of providing durable ceramic veneered zirconia to withstand simulated oral physiologic masticatory function and assured for clinicians to adopt for diary practice. Nonetheless, the fracture resistance in the CAD-fused was significantly higher than in the CAD-bonded-groups upon the artificial aging process. ${ }^{28}$ In addition, one study mentioned that there was no significant difference in the biaxial fracture strength and Weibull modulus of the ceramic veneered zirconia upon the veneering process between heat-pressed and CAD-fused techniques, ${ }^{30}$ which 

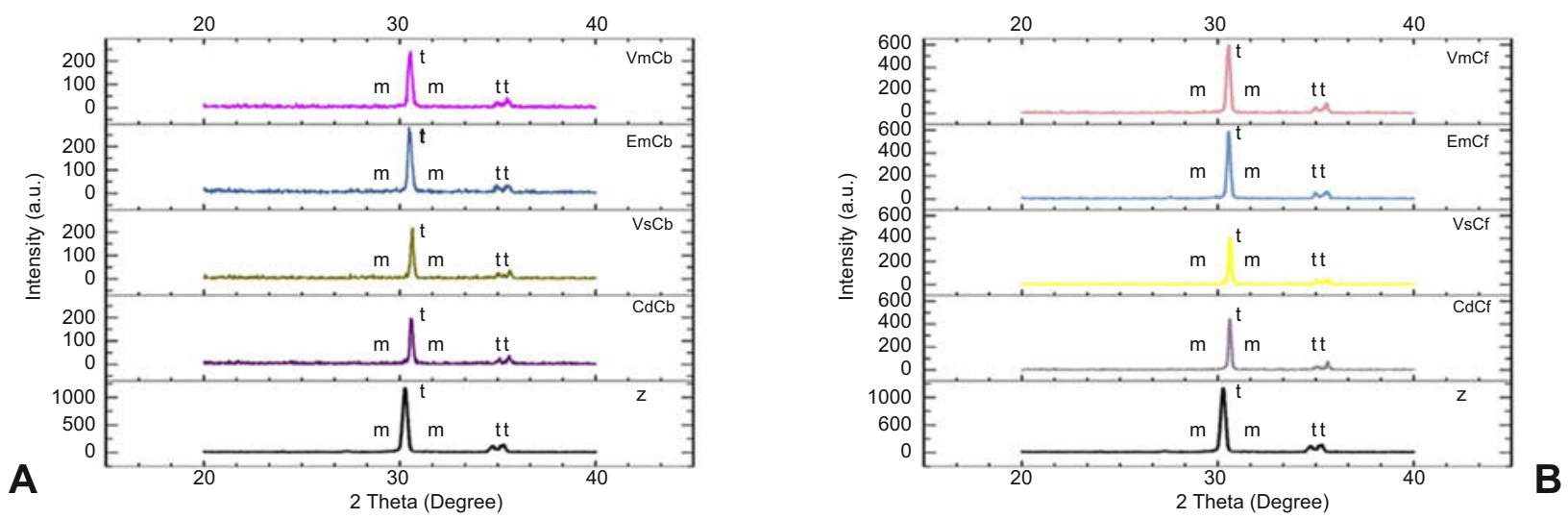

Figure 3 XRD photomicrographs display crystal structure primarily in tetragonal ( $t)$ phase, with minor amount of monoclinic (m) phase for Vitabloc (Vm), e.max CAD (Em), Vita Suprinity (Vs), Celtra Duo $(C d)$ ceramic veneered zirconia $(Z)$ with either $(\mathbf{A})$ CAD-bonded- $(C b)$ or $(B)$ CAD-fused $(C f)$ ceramic veneering procedure.

comparatively supported the reliability of strength of novel computerized veneering ceramic hybridized on translucent zirconia, and only limited to compressive load test as investigated in this study. Further study on fatigue test may require.

The strength of the ceramic veneered zirconia substructure was also related to the ceramic veneered zirconia bond strength. ${ }^{19}$ The bond strength between the ceramic veneered layer and the zirconia disc was dependent on several variables. Many researchers reported the effect of the CTE mismatch and residual stresses on the failure of bilayer ceramics. ${ }^{19-21}$ Due to the possible increase in tensile stress, the difference in the thermal expansion between ceramics should be as small as possible. ${ }^{23,26}$ It was revealed that the CTE of core and veneer match caused high loads to failure. The load to failure was reduced when the CTE of veneer materials became increasingly greater than the CTE of core materials. ${ }^{24}$ The CTE $\left(\times 10^{-6} / \mathrm{K}\right)$ of $\mathrm{Vm}, \mathrm{Em}, \mathrm{Vs}, \mathrm{Cd}$ and $\mathrm{Z}$ are 9.4 $\pm 0.1,10.1 \pm 0.5,12.3,11.8$, and 11 respectively. The acceptable range of CTE mismatch between zirconia and ceramic veneering materials was reported to be within $1.0-1.7 \times 10^{-6} \mathrm{~K}^{-1} \cdot{ }^{21}$ For the $\mathrm{Cb}$ technique, the CTE mismatch might not be the problem since resin cement was used to bond each part together. The CTE of the Vm and the zirconia substructure was the highest of the veneering material used in this study; consequently, these two ceramics had the lowest combined biaxial flexural strength. In this study, the positive CTE mismatch between the two layers (CTE of veneering material was lower than that of the core ceramic in $\mathrm{Vm}$ and Em groups) resulted in the veneer going into compression during the cooling process; consequently, the compressive residual stress may have helped to resist crack propagation and minimize failure in the ceramic. The ZLS ceramics including Vs and Cd have higher CTE value than the zirconia substructure; however, they are within the acceptable range. For the calculations of bi-layered specimen, the formula dictates that the strength is determined mainly by the variables $\mathrm{m}$ and $v$. Although most ceramics have the same $v$ variable, the most important of the variable in this equation is $\mathrm{m}$. The higher the value of $\mathrm{m}$, the greater the strength expected to be obtained. ${ }^{27}$ Table 1 showed the values of $\mathrm{m}$ for the various materials; however, the results of the experiment did not directly correspond to the value of $\mathrm{m}$. This was because when failure occurred, the cracks started from the base and moved upward through the ceramic zirconia bond toward the veneer, meaning that bonding might have also played an important role in the results. The microscopic evaluation of the zirconia-veneer interface showed that it was difficult to recognize the interface between the veneer versus glass fusing ceramic and the interface between glass fusing ceramic and zirconia substructure in the $\mathrm{Cf}$ technique, suggesting that the glass successfully fused the two ceramic layers, in agreement with the previous study. ${ }^{10,28}$ For the fracture surface evaluation, it was interesting to note that the fracture patterns of the $\mathrm{Cb}$ groups were different from the $\mathrm{Cf}$ groups as their patterns were perpendicular whereas that of the $\mathrm{Cf}$ groups were oblique. This indicated that $\mathrm{Cf}$ technique is better of enhancing fracture resistance of ceramic veneered zirconia than $\mathrm{Cb}$ technique. Additionally, XRD showed a more monoclinic phase in the $\mathrm{Cf}$ group; the phase transformation might be a result of the thermal residual stress of the fusion ceramic or as a result of a certain mismatch of CTE in both layers. 


\section{Conclusions}

The result of this study indicated that the flexural strength of $\mathrm{CAD} / \mathrm{CAM}$-fabricated ceramic veneered translucence zirconia was affected by the type of veneering ceramic, hybridization technique, and their interactions. Computerized generatedeither conventional feldspathic-, lithium disilicate- or zirconiareinforced lithium silicate veneering ceramic was capable of conjugating to translucence zirconia either by CAD-bondedor CAD-fused veneering techniques. Nevertheless, the CADfused technique seems to provide higher flexural strength than the CAD-bonded technique. In order to produce a better clinical outcome, the CAD-fused technique was preferable and suggested for hybridization of computerized machinable ceramic veneered zirconia to enhance fracture resistance.

\section{Clinical significance}

The flexural strength of the machinable ceramic veneered zirconia restoration was influenced by the veneering material, hybridized technique, and their interactions. Computerized machinable feldspathic-, lithium disilicate-, and zirconiareinforced lithium silicate-veneering ceramic are able to couple with zirconia using either CAD-fused or CAD-bonded techniques. However, the CAD-fused technique is capable of enhancing reliability on fracture resistance of ceramic veneered zirconia and was suggested for clinical practice.

\section{Disclosure}

The authors do not have any financial interest with companies whose materials are included and report no conflicts of interest in this work.

\section{References}

1. Bachhav VC, Aras MA. Zirconia-based fixed partial dentures: a clinical review. Quintessence Int. 2011;42:173-182.

2. Alghazzawi TF, Lemons J, Liu PR, Essig ME, Janowski GM. Evaluation of the optical properties of CAD-CAM generated yttria-stabilized zirconia and glass-ceramic laminate veneers. $J$ Prosthet Dent. 2012;107:300-308. doi:10.1016/S0022-3913(12) 60079-1

3. Sailer I, Pjetursson BE, Zwahlen M, Hammerle CH. A systematic review of the survival and complication rates of all-ceramic and metal-ceramic reconstructions after an observation period of at least 3 years. Part II: fixed dental prostheses. Clin Oral Implants Res. 2007;18:86-96. doi:10.1111/j.1600-0501.2007.01468.x

4. Al-Amleh B, Lyons K, Swain M. Clinical trials in zirconia: a systematic review. J Oral Rehabil. 2010;37:641-652. doi:10.1111/ j.1365-2842.2010.02094.x

5. Daou EE. The zirconia ceramic: strengths and weaknesses. Open Dent J. 2014;8:33-42. doi:10.2174/1874210601408010033

6. Heintze SD, Rousson V. Survival of zirconia- and metal-supported fixed dental prostheses: a systematic review. Int J Prosthodont. 2010;23:493-502.
7. Zhang Y. Making yttria-stabilized tetragonal zirconia translucent. Dent Mater. 2014;30:1195-1203. doi:10.1016/j.dental.2014.08.375

8. Traini T, Gherlone E, Parabita SF, Caputi S, Piattelli A. Fracture toughness and hardness of a Y-TZP dental ceramic after mechanical surface treatments. Clin Oral Investig. 2014;18:707-714. doi:10.1007/s00784-013-1018-z

9. Beuer F, Schweiger J, Eichberger M, Kappert HF, Gernet W, Edelhoff D. High-strength CAD/CAM-fabricated veneering material sintered to zirconia copings-a new fabrication mode for all-ceramic restorations. Dent Mater. 2009;25:121-128. doi:10.1016/j.dental.2008.04.019

10. Basso GR, Moraes RR, Borba M, Griggs JA, Della Bona A. Flexural strength and reliability of monolithic and trilayer ceramic structures obtained by the CAD-on technique. Dent Mater. 2015;31:1453-1459. doi:10.1016/j.dental.2015.09.013

11. Oh SH, Kim SG. Effect of abutment shade, ceramic thickness, and coping type on the final shade of zirconia all-ceramic restorations: in vitro study of color masking ability. $J$ Adv Prosthodont. 2015;7:368-374. doi:10.4047/jap.2015.7.5.368

12. Griggs JA. Recent advances in materials for all-ceramic restorations. Dent Clin North Am. 2007;51:713-727. doi:10.1016/j.cden.2007.04.006

13. Schmitter M, Mueller D, Rues S. Chipping behaviour of all-ceramic crowns with zirconia framework and $\mathrm{CAD} / \mathrm{CAM}$ manufactured veneer. $J$ Dent. 2012;40:154-162. doi:10.1016/j.jdent.2011.12.007

14. Bindl A, Luthy H, Mormann WH. Strength and fracture pattern of monolithic CAD/CAM-generated posterior crowns. Dent Mater. 2006;22:29-36. doi:10.1016/j.dental.2005.02.007

15. Awad D, Stawarczyk B, Liebermann A, Ilie N. Translucency of esthetic dental restorative $\mathrm{CAD} / \mathrm{CAM}$ materials and composite resins with respect to thickness and surface roughness. J Prosthet Dent. 2015;113:534-540. doi:10.1016/j.prosdent.2014.12.003

16. Elsaka SE, Elnaghy AM. Mechanical properties of zirconia reinforced lithium silicate glass-ceramic. Dent Mater. 2016;32:908-914. doi:10.1016/j.dental.2016.03.013

17. Saito A, Komine F, Blatz MB, Matsumura H. A comparison of bond strength of layered veneering porcelains to zirconia and metal. J Prosthet Dent. 2010;104:247-257. doi:10.1016/S0022-3913(10) 60133-3

18. Studart AR, Filser F, Kocher P, Luthy H, Gauckler LJ. Mechanical and fracture behavior of veneer-framework composites for all-ceramic dental bridges. Dent Mater. 2007;23:115-123. doi:10.1016/j.dental.2005.12.009

19. Aboushelib MN, de Jager N, Kleverlaan CJ, Feilzer AJ. Microtensile bond strength of different components of core veneered all-ceramic restorations. Dent Mater. 2005;21:984-991. doi:10.1016/j.dent al.2005.03.013

20. de Kler M, de Jager N, Meegdes M, van der Zel JM. Influence of thermal expansion mismatch and fatigue loading on phase changes in porcelain veneered Y-TZP zirconia discs. $J$ Oral Rehabil. 2007;34:841-847. doi:10.1111/j.1365-2842.2006.01675.x

21. Fischer J, Stawarczyk B, Tomic M, Strub JR, Hammerle CH. Effect of thermal misfit between different veneering ceramics and zirconia frameworks on in vitro fracture load of single crowns. Dent Mater J. 2007;26:766-772.

22. Juntavee N, Dangsuwan C. Role of coefficient of thermal expansion on bond strength of ceramic veneered yttrium-stabilized zirconia. J Clin Exp Dent. 2018;10(3):e279-e286. doi:10.4317/jced.54605

23. De Jager N, Pallav P, Feilzer AJ. The influence of design parameters on the FEA-determined stress distribution in CAD-CAM produced all-ceramic dental crowns. Dent Mater. 2005;21:242-251. doi:10.1016/j.dental.2004.03.013

24. Aboushelib MN, Feilzer AJ, de Jager N, Kleverlaan CJ. Prestresses in bilayered all-ceramic restorations. J Biomed Mater Res B Appl Biomater. 2008;87(1):139-145. doi:10.1002/jbm.b.31083

25. Zeighami S, Mahgoli H, Farid F, Azari A. The effect of multiple firings on microtensile bond strength of core-veneer zirconia-based all-ceramic restorations. J Prosthodont. 2013;22:49-53. doi:10.1111/ j.1532-849X.2012.00889.x 
26. Taskonak B, Mecholsky JJ, Anusavice KJ. Residual stresses in bilayer dental ceramics. Biomaterials. 2005;26:3235-3241. doi:10.1016/j.biomaterials.2004.08.025

27. Guazzato M, Proos K, Quach L, Swain MV. Strength, reliability and mode of fracture of bilayered porcelain/zirconia (Y-TZP) dental ceramics. Biomaterials. 2004;25:5045-5052. doi:10.1016/j. biomaterials.2004.02.036

28. Schmitter M, Schweiger M, Mueller D, Rues S. Effect on in vitro fracture resistance of the technique used to attach lithium disilicate ceramic veneer to zirconia frameworks. Dent Mater. 2014;30:122-130. doi:10.1016/j. dental.2013.10.008
29. Hsueh CH, Kelly JR. Simple solutions of multilayered discs subjected to biaxial moment loading. Dent Mater. 2009;25:506-513. doi:10.1016/j.dental.2008.10.002

30. Lin WS, Ercoli C, Feng C, Morton D. The effect of core material, veneering porcelain, and fabrication technique on the biaxial flexural strength and weibull analysis of selected dental ceramics. J Prosthodont. 2012;21:353-362. doi:10.1111/j.1532-849X.2012.00845.x

\section{Publish your work in this journal}

Clinical, Cosmetic and Investigational Dentistry is an international, peer-reviewed, open access, online journal focusing on the latest clinical and experimental research in dentistry with specific emphasis on cosmetic interventions. Innovative developments in dental materials, techniques and devices that improve outcomes and patient satisfaction and preference will be highlighted. The manuscript management system is completely online and includes a very quick and fair peer-review system, which is all easy to use. Visit http://www.dovepress.com/testimonials.php to read real quotes from published authors. 